\title{
Investigating the Impact of Risk Management on Project Performance in Construction Industry: Evidence from Nigeria
}

\author{
Abdulkarim Ahmed Bukar, Umar Abbas Ibrahim \\ Department of Business Administration, Nile University of Nigeria, Abuja, Nigeria \\ Email address: \\ aabukar5@yahoo.com (A. A. Bukar), abbas.ibrahim@nileuniversity.edu.ng (U. A. Ibrahim)

\section{To cite this article:} \\ Abdulkarim Ahmed Bukar, Umar Abbas Ibrahim. Investigating the Impact of Risk Management on Project Performance in Construction \\ Industry: Evidence from Nigeria. Science Journal of Business and Management. Vol. 9, No. 3, 2021, pp. 224-230. \\ doi: $10.11648 /$ j.sjbm.20210903.20
}

Received: August 2, 2021; Accepted: August 27, 2021; Published: September 7, 2021

\begin{abstract}
The construction industry is highly risky and clogged with many uncertainties especially with the continued surging of COVID-19 pandemic. Evidence abounds on the severity of the impact leading in increase in project abandonment, cash inflow and jobs losses. The purpose of the research is to examine the impact of risk management on project performance of construction industry in Nigeria. A quantitative research design was used and adopting a descriptive study for more in-depth into the risks and risk management issues in the industry. Survey questionnaires used in collecting data from 84 sample respondents. Data generated were analysed using simple linear regression model. The results revealed that risks (internal and external) and risk management significantly impacted on project performance. The research paper, therefore, presents the result of study conducted among the major stakeholders (contractors, consultants, and the client) of projects in Abuja, Lagos and Portharcourt all in Nigeria. In addition, the result revealed that the major problem of the construction industry in risk is the lack of a regulatory framework to be imbibed and implemented by the companies and firms in the industry. The framework is to be created and monitored by the Bureau of Public Procurement (BPP) and the monitoring process is to include risk audits, risk reassessment, risk technical performance, reserve analysis and status meeting. The study contributes to better management of risks in the construction industry to reduce impact on project performance.
\end{abstract}

Keywords: Risk Management, Internal Risks, External Risks, Project Cost, Project Schedule, Project Scope

\section{Introduction}

Despite the global increase in the development of different projects in construction industry, it is still behind other industries due to several challenges [19]. The impact of the snail growth, due to the challenges in the industry, is more felt in developing and emerging economies where the industry plays vital role in boosting economic macro (GDP) and micro (SMEs) variables [22]. Research has revealed that the industry contributes about $6 \%$ to the global GDP [17]. The challenges have, however, made the industry highly risky [18]. Some of the risks related to construction industry include: 1) Construction risks, which are related to site conditions, labour efficiency etc. 2) The physical risks which are related to damage to structure, injury to labour etc. 3) technical risks are related to incomplete designs, scope change etc. 4) financial risks are related to increase in market cost, delays in payment etc. 5) organisational risks are related to unnecessary work power and communication, conflict of interests etc. 6) environmental risks are related to natural disasters, weather or climate changes etc. 7) socio-political risks are related to bribery and corruption, language and cultural barriers etc. [18]. Managing these risks is highly imperative so that the projects can be successfully executed without failures, and which can be achieved through risk management. This would further increase the chances of opportunities and decrease the chances of threats; and it is worthy to note that risks cannot be completely eliminated but can be managed throughout the project [16]. Risk management is carried out through five processes which are 1) plan risk, 2) risk identification, 3) qualitative risk analysis, 4) quantitative risk analysis, 5) 
plan risk response and control risk [4].

Sadly, the practice of effective risk management that would involve the implementation of risk management processes is either completely absent or at very low stage in the Nigeria construction industry. Whereas the practice and the use of the processes would lead to early detection of the risks that can enhance project managers' ability to manage them and to achieve successful project completion on schedule and at reasonable costs [15]. The reasons why risk management practice is still at infant stage in the Nigeria construction industry is due to knowledge gap and inadequate experienced manpower to handle the processes of risk management [20].

Generally, it is the non-implementation of these risk management practices and processes that has resulted in abandonment and failures of projects and by so doing affected the development of the industry; this has discouraged some investors, both local and foreign, from taking interest to invest in the industry [9].

Effective risk management can be said to involve early detection of risks for analysis so that best decisions for suitable actions necessary for mitigating the risks can be take [9]. In addition, effective risk management involves performing three stages of activities, which are; 1) inputs, 2) processing, and 3) outputs. These activities are carried out using the right risk management tools and techniques which includes brainstorming, decision trees, interviews of experts, checklists etc. [20]. However, sometimes when the risks are identified, analysed and risk responses are assigned to them, the responses are later not suitable for the risks again, during the course of the execution of the projects due to other risks that must have occurred thereby invalidating the responses assigned to the risks earlier identified. This call for reassigning another risk response to make it valid and be able mitigates the risk when it occurred. Some of the responses include avoidance, transfer, relocation, reduction and preservation [6].

It is, therefore, imperative to start risk management practices from feasibility phase of every project where decisions for go or no-go with the project is taken. It is a common fact that the phase contains more risks than any other and as such all the project risks should be addressed and planned for adequately before commencement [7]. It is against this backdrop that the research aims to investigate the impact of risk management (practices and processes) on project performance in the Nigeria Construction Industry in Abuja, Lagos and Port Harcourt, Nigeria.

The absence of risk management practices and processes in the Nigeria Construction Industry has led to many project failures, collapses and abandonment thereby causing the under development of the industry over the years. However, several studies on the impact of risk management on project performance were reviewed but non focused, specifically, on the impact of risk management strategies for managing political, security and communication risks on project performance. The few studies conducted focused on examining the practices adopted for managing risks in the
Nigeria Construction Industry [20], the impact of cost control on risk management [9], sustainable risk management [15], examining the risk management practices in the Nigeria Construction Industry [2]. This study, therefore, aims at surveying the main stakeholders of projects (contractors, consultants and clients) in the Nigeria Construction Industry in Abuja, Lagos and Portharcourt to determine to what extent their knowledge of risk management in the area of security, political and communication is employed on their projects and how can that be improved upon and sustained, going forward, for successful completion of projects.

The aim of the study is to investigate the impact of risk management on project performance in the Nigeria Construction Industry, with specific objects as follows:

i. To examine the impact of security risk on project performance in the Nigeria Construction Industry.

ii. To determine the impact of political risk on project performance in the Nigeria Construction Industry.

iii. To ascertain the impact of communication risk on project performance in the Nigeria Construction Industry.

The study, therefore formulated testable statement of hypotheses used as follows:

$\mathrm{Ho}_{1}$ : There is no significant relationship between the security risk and project performance in the Nigeria Construction Industry.

$\mathrm{Ho}_{2}$ : There is no significant relationship between political risk and project performance in the Nigeria Construction Industry.

$\mathrm{Ho}_{3}$ : There is no significant relationship between communication risk and project performance in the Nigeria Construction Industry.

The study covers the selected Government projects from the public sector within a time frame of one year, from June 2019 to June 2020 . The population of the study is targeted at five hundred and twenty (520) participants from Government owned projects drawn from Federal Capital Territory (Abuja), Lagos and Port-Harcourt.

The independent variables which is the risk management is divided into external and internal sources of risk that impact the project performance. The external (systemic) sources of risk are the risks external to the project while the internal sources of risk are the risk internal (structural) to the project. The dependent variable is the project performance (cost and schedule) which is being impacted upon by the risk management.

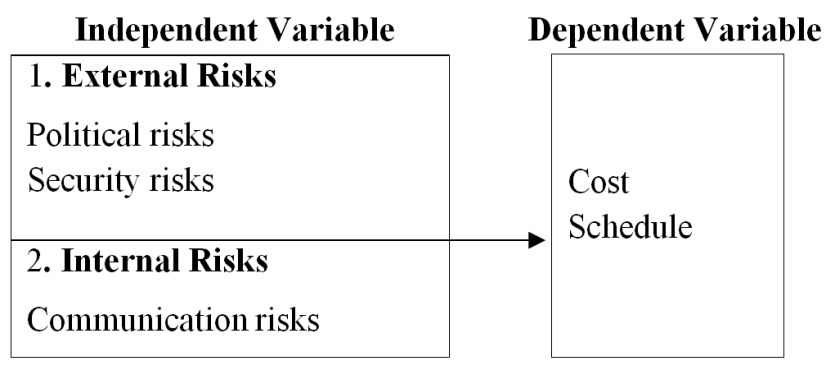

Figure 1. Conceptual Framework. 
The external sources of risk include environmental, security, political, technical and market. Environmental source of risk is the risk from natural and other environmental factors such as pandemic, hurricanes, earthquakes, hailstorm, waste, emissions, accidents and spills etc. Security source of risk is the potential for losses due to physical or cybercrimes and in the case of Nigeria it includes kidnaping of the key personnel of the projects by gunmen attacking the site of the project, computer or cyber security crimes etc. Political source of risk is the probability that political decisions, events or conditions can lead to losses, and it includes policies, legislation, political instability etc. Technical source of risks is the potential for technology changes to result in losses and it includes operational risks, legacy technology (that which is out of date to the extent that it is difficult to maintain and at risk of failure), innovation risk (associated with experimentation and aggressive rates of change), infrastructure risk (failure of basic services such as networks, power and computing resources), etc. Market risk is the risk of losses arising from movements in market variables like prices and volatility. Market risk is also referred to as systematic risk which cannot be eliminated through diversification but can be hedged in other ways and it includes changes in equity prices, changes in commodity prices movements, foreign exchange fluctuations, etc. From the above mentioned sources of risk, is only the political and security risks sources are adopted due to the current happenings in the political scene and the security challenges in the Country and also based on the data collected form the respondents and have the highest ratings.

Internal sources of risk include communication, capacity, capability, corporate governance, and culture. Communication risk is the potential for losses due to poor communication, documentation etc. The Project Manager spend $90 \%$ of his or her time communicating in order to communicate and manage risk [16]. Capacity risk is the potential for losses due to failures from all the strengths and resources available within the project which it supposed to use to manage and reduce risks. Capability risk is the risk associated with the failures from the ability, knowledge, and skills to manage the project and it includes lacking in technical know-how, etc. Culture risk is the risk associated with failures that results from poor beliefs, values and behaviour. From the above mentioned sources of risk is only the communication that is adopted based on the data collected form the respondents and has the highest ratings.

Dependent variable which is the project performance is divided into five dimensions, project scope, project cost, project time, quality and profitability. Project scope is the total work to be executed on the project to generate expected deliverables. Project cost is the total funds available for the execution of the project and it includes direct and indirect costs. Project schedule is the total period required to start and complete the project. Quality is the degree to which the product of the project meets the customer expectation [16]. Profitability is the ability of a company to use its resources to generate revenues in excess of its cost and expenses. From all the proxies, the study adopted the project cost and schedule based on the highest ratings obtained from the respondents.

The study adopted Modern Portfolio Theory for its relevance to the variables.

MPT was pioneered in 1952 by famous American economist Harry Markowitz and his British associate Andrew Donald Roy [12]. MPT states that an efficient portfolio is the one that either give high returns or low risks exposure. It suggests choosing different assets to form portfolio in order to reduce the risks of loss [5].

The MPT makes various assumptions and amongst them are: 1) Investors do not want to take risk, 2) Investors' decisions are based on expected returns for a given level of risk, 3) Investors create wealth by maximizing returns, 4) Investors considers risk-return relationship over the same time horizon, 5) There are no taxes and transaction cost [10].

Critics of the MPT argued that despite the great work, the assumptions are unrealistic. Some of the key criticisms include: In reality, investors go for highly risky investments as against the assumption that investors are rational and seek to maximise returns while minimising risks. Similarly, there exist information asymmetry between company managers and investors, and, also, there exist taxes and transaction costs that are incurred during investments. Finally, they argued that there is no normal distribution of returns and the investors are also not rational as they invest based on their gut feelings or rumours. Therefore, they concluded that though the theory provided bases for understanding of investments especially evaluation of portfolios, it has flaws which made it not very suitable for todays' world of imperfect markets [21].

The review of previous studies are divided into three groups based on whether they focused on financial performance, non-financial performance or both financial and non-financial performances. Each group is discussed in the succeeding subsections.

Adeusi et al., examined the effect of risk management on the financial performance of Nigerian banks [1]. The risk management was conceptualised using three dimensions; 1) Liquidity risk, 2) credit risk and 3) capital risk and these were measured using four techniques or tools while performance was conceptualized using tree dimensions; 1) return on capital employed (ROCE), return on asset (ROA) and return on equity (ROE) and these were measured using 9-item model. Data on risk management and performance were collected from annual reports and financial statements of 10 Nigerians banks. The data collected were analysed using panel data estimation technique and the result revealed that the three dimensions of risk management had significant impact on performance.

Similarly, Mohammed and Knapkova investigated the relationship between total risk management and company's performance of company's listed in the Prague Stock Exchange, Czech Republic [13]. The total risk management was conceptualised using two dimensions; 1) Total risk management and 2) Intellectual Capital and these were measured using standard deviation of yearly sales over 
standard deviation of economic returns and market value of outstanding stock over book value of the firm respectively. Data on total risk management and company performance were collected from 12 companies listed in the Prague Stock Exchange. The data were analysed using linear regression model and the result revealed that there is a positive and significant relationship between total risk management and company performance.

Hoffmann et al., identified the uncertainty, supply risk management and their impact on performance among the German speaking countries [8]. The risk management was conceptualised using three dimensions; 1) Risk monitoring, 2) Risk mitigation and 3) Risk management process maturity and were measured using twenty-one (21) risk indicators for the risk monitoring, twenty-two (22) risk strategies for the risk mitigation and five-point Likert scale for the risk management process maturity while the dependent variable (risk management performance) was measured using fivepoint Likert scale. Data on risk management and risk management performance were collected from consortium of 13 companies of German speaking countries. The data collected were analysed using partial least square (pls) and the result revealed that the three dimensions of risk management had significant impact on risk management performance.

Similarly, Kinyua et al., established the effects of risk management strategies on project performance of small and medium information and communication technology enterprises in Nairobi, Kenya [11]. The risk management strategies were conceptualised using two main dimensions; 1) project risk assessment and 2) project risk identification these were measured using 8-items questionnaire and 10items questionnaire respectively while project performance was conceptualised using four dimensions; 1) project timelines, 2) schedule, 3) quality of product achieving objectives and 4) profitability and these were measured using 5-items questionnaire. Data on risk management strategies and project performance were collected from 48 ICT SMEs. The data collected were analysed using multiple regression and the result revealed that the two main dimensions of risk management strategies had positive and significant impact on project performance.

Akinbile et al., also conducted a research on risk management and its influence on construction project in Southwestern part of Nigeria [3]. Risk management was conceptualized using three dimensions; 1) Construction related risks, 2) Organisation and environmental related risks and 3) Construction Coordinating related risks and these were measured using 6-items questionnaire, 5-items (organisation) and 2-items (environmental) and 14-items questionnaire, respectively while the construction project was conceptualized using six dimensions; 1) project cost, 2) completion time, 3) productivity, 4) project quality, 5) project health and safety and 6) environmental sustainability and these were measured using 6-items questionnaire. Data for risk management and construction project were collected from 74 construction professionals in both private and public sector within the southwestern part of Nigeria. The data collected were analysed using frequency and descriptive statistical tools and the result revealed that three dimensions of risk management had influence on construction projects.

\section{Methodology}

The study adopted descriptive research methodology was used as the researcher seeks to know more about the existence of risk management in the construction industry and how it has impacted project performance in the Country, especially, during the period under review. This section of the study shows the research hypothesis postulated. The main focus is on the research design, type and sources of data, population description, sample size, sampling technique and a description of the choice of the data collection instrument and method of data measurement.

This study was carried out in three (3) major cities currently experiencing mega construction in Nigeria and they are Federal Capital territory (Abuja), Lagos and Portharcourt. Abuja is known to be the power seat of the Nation and expected to have myriad of construction works ongoing, similarly, Lagos is known to be the biggest commercial hub in Nigeria and presently experiencing construction boom on different capacities and lastly Portharcourt which is a major city in the Niger Delta region of the Country, is also experiencing massive development in the area of construction due to the presence of oil companies [20].

Sample Population and Size

The study adopted cross-sectional survey research design. The primary data is achieved through the administration of structured questionnaire to the respondents under selected projects in the three cities of Abuja, Lagos and Portharcourt.

The study population is 520 participants drawn from the construction companies, Consultancy firms and the client of the selected projects. The 520 participants are spread over the 3 cities. Participants are categorised into three, the contractors, consultants and client. The participants on the side of the contractors and consultants must be from companies and firms registered with the Bureau of Public Procurement (BPP) under the National Database of Contractors, Consultants and Service Providers (CCSPS).

The sample size of 84 is obtained using Taro Yamane formula, 1967 statistical equation $\left\{\left(n=N / 1+N(e)^{2}\right\}\right.$. Simple random stratified sampling technique is used to select the companies and firms from which the 84 participants are drawn. The 84 participants are spread among the 3 cities with Abuja being the seat of power having 30 while the remaining 2 cities have 27 participants each.

\section{Result}

The data generated through the administered structured questionnaire were analysed using multiple linear regression.

Out of the 84 questionnaires administered online, 75 responses were received but three were incomplete and therefore, only 75 were analysed. From the 75 respondents; 
26 are building contractors, 17 are other civil contractors, 8 are project managers (consultants), 14 are other consultants, and 7 are the clients. A total of 49 are male while 23 are female. For the ages of the respondents, 11 indicated between 20 and 30 years of age, 21 between 30 and 40.27 between 40 and 50 and 13 are above 50 . On the years of experience, 18 respondents indicated between 5 and 15, 32 are between 15 and 25 while 22 are between 25 and 35 . This indicated that the majority of the respondents are highly experienced. For the number of employees, 5 respondents indicated their staff strength is between 10 to 20,15 ticked between 20 to 30,22 indicated between 30 to 40,13 marked between 40 to 50 and 17 ticked 50 and above.

On the awareness of risks and risk management processes; 2 respondents indicated they are not aware, 9 indicated they are aware and got the knowledge from experience, 33 ticked that they are aware and got the knowledge from training, 15 indicated that they are aware and got the knowledge from studies while 12 indicated that they are aware and got the knowledge from news and experience. This indicated that majority of the companies and firms are aware of risks and risks management, but the problem is the implementation of the risk processes, weak risk practises and culture.

The data collected was analysed using simple linear regression model. The model is as given below:

$$
\mathrm{Y}=\beta_{0}+\beta_{1} \mathrm{X}+\varepsilon
$$

where $\mathrm{Y}$ is the dependent variable, $\beta_{0}$ is the intercept or constant, $\beta_{1}$ is the slope or coefficient of $\mathrm{X}$ and $\varepsilon$ is the error term.

\section{Risk Management Processes}

The system for Monitoring and measuring risks and risk management processes in the construction industry, to be complied with, by all registered companies and firms, will involve five basic processes: risk reassessment, risk audits, reserve analysis, status meetings and technical performance. The risk reassessment, reserve analysis and status meetings would be performed by the companies and firms while the risk audits and technical performance would be by the regulatory body. The technical performance will also include the following performance indices:

Cost performance index:

$$
\mathrm{CPI}=\mathrm{PV} / \mathrm{AC}
$$

Where PV is planned value (as of today, what is the estimated value of the work planned to be done) and $\mathrm{AC}$ is the actual cost or total cost (as of today, what is the actual cost incurred for the work accomplished). Getting \$ worth of work out of every $\$ 1$ spent; greater than 1 is good, [14].

Schedule performance index:

$$
\mathrm{SPI}=\mathrm{EV} / \mathrm{PV}
$$

Where EV is the Earned Value (as of today, what is estimated value of work accomplished) and PV is planned value (as of today, what is the estimated value of the work planned to be done). Progress at a percent of the rate originally planned; greater than 1 is good. Mulcahy et al., (2013).

\section{Discussion}

In this section, the regression results obtained from the regression tool pack are used to test the 3-null hypothesis. The hypothesis is tested using the P-Value from the regression model which is set against significance level of 0.05. If the P-Value is less than 0.05, the null hypothesis is rejected and thus conclude that the effect of independent variable on the dependent variable is statistically significant. Otherwise, the null hypothesis is accepted and thus conclude that the effect of the independent variable on the dependent variable is not statistically significant.

$\mathrm{Ho}_{1}$ : There is no significant relationship between the security risk and project performance in the Nigeria

\begin{tabular}{|c|c|c|c|c|c|c|c|}
\hline \multicolumn{8}{|c|}{ SUMMARY OUTPUT } \\
\hline \multicolumn{8}{|c|}{ Regression Statistics } \\
\hline Multiple R & 0.94351215 & & & & & & \\
\hline R Square & 0.89021518 & & & & & & \\
\hline Adjusted R Square & 0.85362024 & & & & & & \\
\hline Standard Error & 3.30009915 & & & & & & \\
\hline Observations & 5 & & & & & & \\
\hline \multicolumn{8}{|l|}{ ANOVA } \\
\hline & $d f$ & $S S$ & $M S$ & $F$ & Significance $F$ & & \\
\hline Regression & 1 & 264.9280369 & 264.9280369 & 24.32618168 & 0.01597909 & & \\
\hline Residual & 3 & 32.67196312 & 10.89065437 & & & & \\
\hline \multirow[t]{2}{*}{ Total } & 4 & 297.6 & & & & & \\
\hline & Coefficients & Standard Error & $t$ Stat & P-value & Lower $95 \%$ & Upper 95\% & Lower $95.0 \%$ \\
\hline Intercept & -1.8421821 & 3.608706486 & -0.510482663 & 0.644903282 & -13.3266967 & 9.642332527 & -13.32669672 \\
\hline $\mathrm{X}$ Variable 1 & 1.12792931 & 0.228688808 & 4.932157913 & 0.015979087 & 0.40013946 & 1.855719163 & 0.400139461 \\
\hline
\end{tabular}
Construction Industry in Abuja, Lagos and Portharcourt.

Table 1. Hypothesis 1 Regression Summary Output.

From the above table, the $\mathrm{P}$-value is 0.015979087 which is far less than 0.05 significance level. The null hypothesis is therefore, rejected and thus conclude that there is statically significant relationship between security risk and project performance. The R-square is also 0.89021518 which is also very good as this indicate that $89 \%$ change in the project 
performance is predicted by the security risk.

$\mathrm{Ho}_{2}$ : There is no significant relationship between political risk and project performance in the Nigeria Construction Industry.

Table 2. Hypothesis 2 Regression Summary Output.

\begin{tabular}{|c|c|c|c|c|c|c|c|c|}
\hline \multicolumn{9}{|c|}{ SUMMARY OUTPUT } \\
\hline \multicolumn{9}{|c|}{ Regression Statistics } \\
\hline Multiple R & 0.97941409 & & & & & & & \\
\hline R Square & 0.95925197 & & & & & & & \\
\hline $\begin{array}{l}\text { Adjusted R } \\
\text { Sauare }\end{array}$ & 0.94566929 & & & & & & & \\
\hline Standard Error & 2.01052355 & & & & & & & \\
\hline Observations & 5 & & & & & & & \\
\hline \multicolumn{9}{|l|}{ ANOVA } \\
\hline & $d f$ & $S S$ & $M S$ & $F$ & Significance $F$ & & & \\
\hline Regression & 1 & 285.4733851 & 285.4733851 & 70.623184 & 0.00353462 & & & \\
\hline Residual & 3 & 12.12661489 & 4.042204965 & & & & & \\
\hline \multirow[t]{2}{*}{ Total } & 4 & 297.6 & & & & & & \\
\hline & Coefficients & Standard Error & $t$ Stat & P-value & Lower 95\% & Upper 95\% & Lower $95.0 \%$ & Upper $95.0 \%$ \\
\hline Intercept & 6.62261097 & 1.290320564 & 5.132531522 & 0.01432501 & 2.51623506 & 10.72898688 & 2.516235057 & 10.7289869 \\
\hline $\mathrm{X}$ Variable 1 & 0.54009646 & 0.064268429 & 8.403760113 & 0.00353462 & 0.33556564 & 0.744627285 & 0.335565636 & 0.74462728 \\
\hline
\end{tabular}

From the above table, the P-value is 0.00353462 which is far less than 0.05 significance level. The null hypothesis is therefore, rejected and thus conclude that there is statically significant relationship between political risk and project performance.

The R-square is also 0.95925197 which is also very good as this indicates that $95 \%$ change in the project performance is predicted by the political risk,

$\mathrm{Ho}_{3}$ : There is no significant relationship between
Communication risk and project performance in the Nigeria Construction Industry.

From the table 3 below, the P-value is 0.006990374 which is far less than 0.05 significance level. The null hypothesis is therefore, rejected and thus conclude that there is statically significant relationship between communication risk and project performance. The $\mathrm{R}$-square is also 0.93610756 which is also very good as this indicates that $93 \%$ change in the project performance is predicted by the communication risk.

Table 3. Hypothesis 3 Regression Summary Output.

\begin{tabular}{|c|c|c|c|c|c|c|c|c|}
\hline \multicolumn{9}{|c|}{ SUMMAARY OUTPUT } \\
\hline \multicolumn{9}{|c|}{ Regression Statistics } \\
\hline Multiple R & 0.96752651 & & & & & & & \\
\hline R Square & 0.93610756 & & & & & & & \\
\hline $\begin{array}{l}\text { Adjusted R } \\
\text { Square }\end{array}$ & 0.91481007 & & & & & & & \\
\hline Standard Error & 2.51756439 & & & & & & & \\
\hline Observations & 5 & & & & & & & \\
\hline ANUVA & $d f$ & $S S$ & $M S$ & $F$ & Significance $F$ & & & \\
\hline Regression & 1 & 278.5856086 & 278.585609 & 43.95390873 & 0.006990374 & & & \\
\hline Residual & 3 & 19.01439143 & 6.33813048 & & & & & \\
\hline \multirow[t]{2}{*}{ Total } & 4 & 297.6 & & & & & & \\
\hline & Coefficients & Standard Error & t Stat & $P$-value & Lower 95\% & Upper 95\% & Lower $95.0 \%$ & Upper $95.0 \%$ \\
\hline Intercept & 7.84590125 & 1.498308165 & 5.23650704 & 0.013554284 & 3.077615966 & 12.6141865 & 3.07761597 & 12.6141865 \\
\hline $\mathrm{X}$ Variable 1 & 0.45514575 & 0.06865177 & 6.62977441 & 0.006990374 & 0.236665175 & 0.67362632 & 0.23666518 & 0.67362632 \\
\hline
\end{tabular}

\section{Conclusion}

The study revealed that the 3 null hypotheses are rejected and thus proving that the three proxy independent variables have statistically significant impact on the project performance. Of the three results, the second independent proxy variable (political risk) has the highest R-Square of $95 \%$. This shows that the political risk has more impact on project performance as they cannot be easily managed or diversified. Finally, the study showed that the major problem of the construction industry in risk is the lack of a regulatory framework to be imbibed and implemented by the companies and firms in the industry.

\section{Recommendations}

It is therefore, recommended as follows:

i. Companies and firms should create awareness programmes such as seminars, conferences and trainings for their personnel in the area of risk. In addition, they should have risk management departments to monitor risk management processes.

ii. Companies and firms should take different insurance policies against the external risks. In addition, they should imbibe the culture of portfolio diversification to 
reduce the severity of the impacts of some of the risks when they crystallised.

iii. The Bureau of Public Procurement should, with immediate effect, establish a risk management framework that must be undertaken by the companies and firms as part of the registration criteria. The implementation of the framework should be periodically monitored and measured by the agency for enforcement. Default by any company or firm should be followed with warnings and sanctions such fines and delisting, where necessary.

The study is not exhaustive as risk has to and should be monitored/tracked and managed continuously. Therefore, areas recommended for future study includes.

i. Another method of data collection should be used. The study used survey questionnaire which was administered online and was not perfect, therefore, another method such as interview can be adopted.

ii. The regulatory framework for monitoring and measuring risk management process should be developed upon to become robust with templates and metrics for easy implementation.

\section{References}

[1] Adeusi, S. O., Akeke, N. I., Adebisi, O. S., \& Oladunjoye, O. (2014). Risk management and financial performance of banks in Nigeria. Risk Management, 6 (31), 123-129.

[2] Adeleke, A. Q., Bahaudin, A. Y., \& Kamaruddeen, A. M. (2015). Level of risk management practice in Nigeria Construction Industry- from a knowledge based approach. Journal of Management Marketing and Logistics, 2 (1).

[3] Akinbile, B. F., Ofuyatano, M., Oni, O. Z., \& Agboola, O. D. (2018). Risk management and its influence on construction project in Nigeria. Annals of the faculty of engineering hunedoara, 16 (3), 169-174.

[4] Appiah, B. L. (2020). Risk Management Processes and Analysis in Projects Construction Industry. Environmental Engineering, 5 (4), 92-101. Performance, 5 (1).

[5] Bundotich, M., \& Maina, K. E. (2020). Effect of Portfolio Diversification Practices on Cash Flow Management among National Technical and Vocational Education and Training Institutions in Uasin Gishu County, Kenya. Journal of Finance, 2, 19.

[6] Ezeabasili, A. C. C., Dim, N. U., Obiefuna, J. J., \& Ezeabasili, C. A. C. Appraising The Management Strategies For Risk Events In The Nigeria Construction Industry.

[7] Ezeabasili, A. C. C., Dim, N. U., Ezeabasili, C. A. C., \& Obiefuna, J. J. (2021). The identification of risks and its criticality in the Nigeria construction industry. International Journal of Engineering and Management Research, 11 .

[8] Hoffmann, P., Schiele, H., \& Krabbendam, K. (2013). Uncertainty, supply risk management and their impact on performance. Journal of purchasing and supply management, 19 (3), 199-211. https://doi.org/10.1016/j.pursup.2013.06.002

[9] Joseph, F., Egwu, K., Agbo, M., \& Nnadi, E. (2020). Project Cost Control for Effective Risk Management in Nigeria Construction Industry. Inosr Applied Sciences, 6 (1).

[10] Khan, A. H., Cao, X., Katsikis, V. N., Stanimirović, P., Brajević, I., Li, S., ... \& Nam, Y. (2020). Optimal portfolio management for engineering problems using nonconvex cardinality constraint: a computing perspective. IEEE Access, 8, 57437-57450.

[11] Kinyua, E., Ogollah, K., \& Mburu, D. K. (2015). Effect of risk management strategies on project performance of small and medium information communication technology enterprises in Nairobi, Kenya. International Journal of Economics, Commerce and Management, 3 (2), 1-30.

[12] Koumou, G. B. (2020). Diversification and portfolio theory: a review. Financial Markets and Portfolio Management, 34, 267-312.

[13] Mohammed, H. K., \& Knapkova, A. (2016). The impact of total risk management on company's performance. ProcediaSocial and Behavioral Sciences, 220, 271-277. https://doi.org/10.1016/j.sbspro.2016.05.499

[14] Mulcahy, R. (2013). PMP Exam Prep, Eight Edition, Library of Congress, RMC Publication Inc. United States of America.

[15] Odumade, A., Urokor, M., \& Onyekweredike, K. (2020). Sustainable Development and Risk Management in Road Construction Industry in Nigeria. Authorea Preprints.

[16] Renault, B. Y., Agumba, J. N., \& Ansary, N. (2020). Establishing Core Factors of Risk Management Influencing Performance Outcome of Small and Medium Firm's Construction Projects in Gauteng. Journal of Construction in Developing Countries, 25 (2), 93-127.

[17] Salas, R., Hallowell, M., Balaji, R., \& Bhandari, S. (2020). Safety risk tolerance in the construction industry: Crosscultural analysis. Journal of construction engineering and management, 146 (4), 04020022.

[18] Sankar, S. D., \& Selvam, J. (2020). Risk Management in Construction Industry. Risk Management, 7 (08).

[19] Sanni-Anibire, M. O., Mohamad Zin, R., \& Olatunji, S. O. (2020). Causes of delay in the global construction industry: a meta analytical review. International Journal of Construction Management, 1-13.

[20] Ugwu, M. C., Osunsanmi, T. O., \& Aigbavboa, C. O. (2019). Evaluation of Risk Management Practice in the Nigeria Construction Industry. Modular and Offsite Construction (MOC) Summit Proceedings, 373-380. https://doi.org/10.29173/mocs116

[21] Vuković, M., Pivac, S., \& Babić, Z. (2020). Comparative analysis of stock selection using a hybrid MCDM approach and modern portfolio theory. Croatian Review of Economic, Business and Social Statistics, 6 (2), 58-68.

[22] Yap, J. B. H., Chow, I. N., \& Shavarebi, K. (2019). Criticality of construction industry problems in developing countries: Analyzing Malaysian projects. Journal of Management in Engineering, 35 (5), 04019020. 